\title{
Role of adenylyl cyclase in reduced $\beta$-adrenoceptor- mediated vasorelaxation during maturation
}

\author{
O.A. López-Canales², M.C. Castillo-Hernandez ${ }^{1}$, H. Vargas-Robles ${ }^{2}$, A. Rios ${ }^{3}$, \\ J.S. López-Canales ${ }^{1,4}$ and B. Escalante ${ }^{3}$ \\ ${ }^{1}$ Pharmacology Department, Superior School of Medicine, Polytechnic National Institute, Mexico City, Mexico \\ ${ }^{2}$ Molecular Biomedicine Department, Center of Research and Advanced Studies, Unidad Zacatenco, Mexico City, Mexico \\ ${ }^{3}$ Center of Research and Advanced Studies, Monterrey, Nuevo León, Mexico \\ ${ }^{4}$ Perinatology National Institute "Isidro Espinosa de los Reyes", Mexico City, Mexico
}

\begin{abstract}
Beta-adrenergic receptor ( $\beta A R$ )-dependent blood vessel relaxation is impaired in older animals and $G$ protein activation has been suggested as the causative mechanism. Here, we investigated the role of $\beta A R$ subtypes ( $\beta 1 A R, \beta 2 A R$, and $\beta 3 A R)$ and CAMP in maturation-dependent vasorelaxation impairment. Aortic rings from 15 Sprague-Dawley male rats ( 3 or 9 weeks old) were harvested and left intact or denuded of the endothelium. Vascular relaxation in aortic rings from younger and older groups was compared in the presence of $\beta A R$ subtype agonists and antagonists along with cAMP and cGMP antagonists. Isolated aortic rings were used to evaluate relaxation responses, protein expression was evaluated by western blot or real time PCR, and metabolites were measured by ELISA. Expression of $\beta A R$ subtypes and adenylyl cyclase was assessed, and cAMP activity was measured in vascular tissue from both groups. Isoproterenol- and BRL744-dependent relaxation in aortic rings with and without endothelium from 9-week-old rats was impaired compared with younger rats. The $\beta 1 A R$ antagonist CGP20712A $\left(10^{-7} \mathrm{M}\right)$ did not affect isoproterenol or BRL744-dependent relaxation in arteries from either group. The $\beta 2 A R$ antagonist $\mathrm{ICl}-118,551\left(10^{-7} \mathrm{M}\right)$ inhibited isoproterenol-dependent aortic relaxation in both groups. The $\beta 3 A R$ antagonist SR59230A $\left(10^{-7} \mathrm{M}\right)$ inhibited isoproterenol- and BRL744-dependent aortic ring relaxation in younger but not in older rats. All $\beta A R$ subtypes were expressed in both groups, although $\beta 3 A R$ expression was lower in the older group. Adenylyl cyclase (SQ 22536) or protein kinase A (H89) inhibitors prevented isoproterenol-induced relaxation in younger but not in older rats. Production of cAMP was reduced in the older group. Adenylyl cyclase III and RyR3 protein expression was higher in the younger group. In conclusion, altered expression of $\beta 3 A R$ and adenylyl cyclase III may be responsible for reduced cAMP production in the older group.
\end{abstract}

Key words: $\beta$ adrenergic receptors; Vascular tissue; Adenyl cyclase

\section{Introduction}

Blood vessel relaxation induced by the catecholamine system is mediated through $\beta$ adrenergic receptors ( $\beta A R)$. Although vascular $\beta A R$ were originally classified as beta 2 $(\beta 2 A R)$ and beta 1 ( $\beta 1 A R)$ adrenergic receptor subtypes, later studies described atypical $\beta$ adrenergic receptors that included $\beta 3 A R(1)$. Further characterization described $\beta 3 A R$ as a relevant mediator in catecholamine-induced vasodilation (2-4). Catecholamine-dependent blood vessel relaxation is impaired in older animals (5). In humans, loss of vascular relaxation in elderly people could contribute to clinical development of hypertension or cardiovascular diseases, as orthostatic hypotension and arterial insufficiency are present in older populations (6). Several authors have explored the mechanism involved in $\beta A R$ dependent impaired vascular relaxation. Initial reports suggested decreased cAMP production and phospho- diesterases as the mechanism involved in the adrenergic vasorelaxation impairment (5). Later on, decreased function of the stimulatory GTP-binding protein ( $G \alpha s$ ) was associated with $\beta 2 A R$-induced vasodilation impairment in aortas from aged rats (7). This idea was further explored by several authors that either supported decreased (8) or increased (9) Gas protein expression as the mechanism for age-dependent adrenergic vasorelaxation impairment. More recently, a differential activation of $\mathrm{G} \alpha$ protein has been suggested as an explanation for this controversy: activation of $\mathrm{G} \alpha$ s decreased, whereas $\mathrm{G} \alpha \mathrm{i}$ increased in older animals (10).

Most of the studies on age-related $\beta A R$-mediated vascular relaxation have focused on $\beta 1 A R$ or $\beta 2 A R$, but few studies have evaluated the role of $\beta 3 A R(1,4)$. However, it has been suggested that the three $\beta A R$ 
subtypes work in concert to render adrenergic vascular relaxation. All $\beta A R$ receptors couple to $G \alpha s$ protein and elicit cAMP production (11). Under normal stimulation, $\beta 2 A R-$ and $\beta 1 A R-d e p e n d e n t$ cAMP production is modulated by PKA phosphorylation, leading to reduced CAMP production and reduced $\beta 2 A R-$ and $\beta 1 A R-m e d i a t e d$ vasorelaxation (12). However, $\beta 3 A R$ does not require this PKA phosphorylation mechanism, which allows a prolonged vasorelaxation effect compared with that induced by $\beta 2 A R$ and $\beta 1 A R$ (13). These combined results suggest that age-dependent changes in adrenergic vasorelaxation could be associated with differential expression of $\beta$-adrenergic receptor second messengers.

Understanding the causes of age-related decline in $\beta A R-m e d i a t e d$ vasodilation-signaling may help identify a therapeutic target for treating cardiovascular diseases. In the present study, we investigated $\beta A R$ subtypes and cAMP-dependent vasorelaxation in maturation-dependent adrenergic vasorelaxation. We evaluated the mechanisms of $\beta A R$-mediated CAMP signaling by testing vasorelaxation and CAMP activity in aortic rings from 3- and 9-week-old rats in the presence of specific $\beta 1 A R, \beta 2 A R$, $\beta 3 A R$, and $C A M P$ antagonists. We also evaluated protein content and mRNA expression of $\beta A R$ in thoracic aorta.

\section{Material and Methods}

Fifteen male Sprague-Dawley rats (3 or 9 weeks old) were used throughout the experiments. Rats were fed with a balanced diet and had water ad libitum. All procedures conformed to the National Institutes of Health "Guide for the Care and Use of Laboratory Animals" (1996) and were approved by the Institutional Ethics Review Committee for Animal Experimentation of the Center of Research and Advanced Studies, IPN (approval No. 479-10).

\section{Preparation of rat aortic rings}

Rats were sacrificed by cervical dislocation. The thoracic aorta was carefully removed, and placed directly into ice-cold Krebs-Henseleit bicarbonate solution (117.8 mM $\mathrm{NaCl}, 6.0 \mathrm{mM} \mathrm{KCl}, 1.6 \mathrm{mM} \mathrm{CaCl}_{2}, 1.2 \mathrm{mM} \mathrm{MgSO}_{4}, 1.2$ $\mathrm{mM} \mathrm{KH}_{2} \mathrm{PO}_{4}, 24.2 \mathrm{mM} \mathrm{NaHCO}_{3}, 11.0 \mathrm{mM}$ glucose, 0.027 mM EDTA), equilibrated with $95 \% \mathrm{O}_{2}$ and $5 \% \mathrm{CO}_{2}, \mathrm{pH}$ 7.4. Then, periadventitial fat was removed. Care was taken during the complete procedure to ensure the integrity of the vascular endothelium. For experiments with endothelium-denuded aortic rings, the endothelium was removed by gently rubbing the intimal surface of the vessels. Aortic rings (3-4 mm wide) were mounted in $5 \mathrm{~mL}$ water-jacketed organ baths at $37^{\circ} \mathrm{C}$ and equilibrated for 1.5 to $2.0 \mathrm{~h}$. A maximum of two aortic rings from either 3- or 9-week-old rats were used simultaneously. Basal tone was set at 1.5 and $2.0 \mathrm{~g}$, respectively. Changes in tension were measured using a pressure transducer (TSD125) connected to a computerized data acquisition system (MP150-BIOPAC, BIOPAC Systems, USA).
This procedure was determined to produce optimal conditions for reproducible isometric force development.

\section{Experimental procedure}

The presence of endothelium was confirmed by assessing the effectiveness of acetylcholine (ACh, $\left.10^{-6} \mathrm{M}\right)$ to relaxed aortic rings pretreated with phenylephrine (PE, $\left.10^{-6} \mathrm{M}\right)$. The endothelium denudation was confirmed by the incapability of aortic rings to relax in response to ACh $\left(10^{-6} \mathrm{M}\right)$. Concentration-response curves for ACh, isoproterenol, dobutamine, salbutamol, BRL3744, and sodium nitroprusside were obtained in aortic rings pretreated with PE by cumulative addition of the drug to the organ bath. The concentration was increased only after maximal response to the previous concentration was attained. Specific inhibitors and antagonists were used as follows: $\beta A R$ antagonists, $10^{-7} \mathrm{M} C \mathrm{CP} 20712 \mathrm{~A}$ for $\beta 1 \mathrm{AR}$, $10^{-7} \mathrm{M} \mathrm{ICl}-118,551$ for $\beta 2 A R$, and $10^{-7} \mathrm{M}$ SR59230A for $\beta 3 A R$; adenylyl cyclase inhibitor, $10^{-7} \mathrm{M}$ SQ22536; PKA inhibitor, $10^{-7} \mathrm{M} \mathrm{H89}$; guanylyl cyclase inhibitor, $10^{-7} \mathrm{M}$ ODQ; and PGK inhibitor, $10^{-7} \mathrm{M} \mathrm{K75823}$. The isoproterenol concentration-response curve or specific agonist curve were determined, then aortic rings were incubated with the inhibitor or antagonist for $30 \mathrm{~min}$, and the isoproterenol concentration-response curves were repeated. Vascular relaxation is reported as percentage, considering basal tension before PE stimulus as $100 \%$ vascular relaxation and $\mathrm{PE}$-induced tension as $0 \%$ vascular relaxation.

\section{Western blot}

Frozen aortas were ground to powder in a mortar and homogenized with ice-cold lysis buffer $(50 \mathrm{mM}$ Tris- $\mathrm{HCl} \mathrm{pH}$ 7.5, $2.5 \mathrm{mM}$ EDTA, $137 \mathrm{mM} \mathrm{NaCl}, 1 \%$ NP40, 5\%glycerol, $1.5 \mu \mathrm{g} / \mathrm{mL}$ leupeptin, $1.0 \mu \mathrm{g} / \mathrm{mL}$ aprotinin, and phenylmethanesulfonyl fluoride (PMSF). Homogenates were centrifuged at $10,000 \mathrm{~g}$ for $10 \mathrm{~min}$ at $25^{\circ} \mathrm{C}$, supernatant was collected, and protein was measured by Bradford's method. Then, 100 $\mu \mathrm{g}$ of protein was mixed with loading buffer $(50 \mathrm{mM}$ Tris$\mathrm{HCl}, \mathrm{pH} 6.5,2 \%$ SDS, $10 \%$ glycerol, $0.02 \%$ bromophenol blue and heated at $100^{\circ} \mathrm{C}$ for $2 \mathrm{~min}$. Protein was detected on $2 \%$ SDS/PAGE gels under reducing conditions, and then transferred to Hybond-P PVDF membranes (Amersham, GE Healthcare, UK). Blots were blocked for 40 min with TBS containing $5 \%$ skim dry milk and $0.5 \%$ Tween 20 . Immunoblot analysis was performed with the following antibodies (Santa Cruz Biotechnology, USA): $\beta 1$-AR (sc568, 1:100), $\beta 2-A R$ (sc-9042, 1:250) (14), anti- $\beta 3-A R$ (sc$1473,1: 500)$ (15) and anti- $\beta 2 A R$ (Ser 355/356, sc-16719, 1:200). Anti-actin antibody (A2066, 1:2000; Sigma-Aldrich, USA) was used as loading control. All antibodies were diluted in blocking solution, and blots were incubated overnight at $4^{\circ} \mathrm{C}$. Blots were then washed three times with TBS containing $0.5 \%$ Tween 20 and incubated with the corresponding horseradish peroxidase-conjugated secondary antibody. Immunoreactive bands were detected by 
enhanced chemiluminescence (Amersham, GE Healthcare) using Kodak BioMax ML film, and analyzed with 1D image analysis software (Kodak, USA). Values for each band are expressed in arbitrary units (AU). All samples from each $\beta A R$ (5 aortas from each age group) were run simultaneously to eliminate intra-assay variation. Blots presented in figures represent one of the five different experiments. The $\beta A R /$ actin densitometry ratios were calculated for each group and are reported as means $\pm S E$.

\section{Gene expression analysis}

Aortas from 3- and 9-week-old rats were homogenized and total RNA was extracted using TRIzol (Life Technologies, USA). RNA integrity was checked in agarose gels, and $1.0 \mu \mathrm{g}$ RNA was used for reverse transcriptase reactions. Gene expression analysis was performed using the FastStart SYBR Green Master (Rox) kit (Roche Applied Science, USA) and a 7500 Real Time Thermal Cycler (Applied Biosystems, USA). Specific primers for adenylyl cyclase subtypes and the calcium-related protein RyR3 target genes are shown in Table 1.

Relative gene expression was normalized to the constitutive expression of $\alpha$-actin. Gene expression values were determined using the $2^{-\Delta \Delta C T}$ formula. Data in figures represent 1 of the 5 different experiments. AR/actin densitometry value ratios were calculated for each group and reported as means $\pm S E$.

\section{cAMP enzyme immunoassay}

Aortic rings were incubated in $500 \mu \mathrm{L}$ of Krebs solution alone or with CAMP-specific phosphodiesterase inhibitor $\left(10^{-7} \mathrm{M}\right.$ rolipram) at $37^{\circ} \mathrm{C}$ in a shaker bath. cAMP stimulation was initiated by adding $10^{-5} \mathrm{M}$ isoproterenol for $15 \mathrm{~min}$. Samples were rapidly frozen after collection, and intracellular cAMP levels were determined using a cyclic AMP EIA kit (Cayman Chemical, USA) according to the manufacturer's instructions.

\section{Statistical analysis}

Concentration-response curves were compared using two-way analysis of variance (ANOVA) and specific differences between concentrations and rats were compared by modified Bonferroni $t$-test. Comparisons between two or more groups were performed by one-way ANOVA

Table 1. Primers used for gene expression assays.

\begin{tabular}{ll}
\hline Primer & Sequence \\
\hline Actin & Forward: 5'-ATGACCCAAGCCGAGAAGG-3' \\
& Reverse: 5'-CGGCCAAGTCTTAGAGTTGTTG-3' \\
ADCY3 & Forward: 5'-TGAGGAGAGCATCAACAACG-3' \\
& Reverse: 5'-TGGTGTGACTCCTGAAGCTG-3' \\
RyR3 & Forward: 5'-ACCAGCAGGAGCAAGTACG-3' \\
& Reverse: 5'-GGGGTCGTGTCAAAGTAGTCA-3' \\
\hline
\end{tabular}

followed by Newman Keuls test to identify specific differences. Statistical analyses were performed using GraphPad Software Prism 5 for Mac OS X version 5.0 (USA). Data are reported as means $\pm S E$ and $P<0.05$ was considered statistically significant.

\section{Results}

\section{Isoproterenol-dependent vascular relaxation}

PE produced similar dose response-dependent contractions in endothelium-intact aortic rings from 3- and 9-week-old rats. Maximal contractions were $1.22 \pm 0.13$ and $1.49 \pm 0.25 \mathrm{~g}$, respectively. In endothelium-denuded rings from 3- and 9-week-old rats, maximal contractions elicited by $P E$ were $1.32 \pm 0.12$ and $1.67 \pm 0.15 \mathrm{~g}$, respectively. Isoproterenol on precontracted (PE treated) aortic rings from 3- and 9-week-old rats produced a concentration-dependent relaxation in vessels from both groups (Figure 1 and Table 2). However, isoproterenolinduced vascular relaxation was lower in aortic rings from 9-week-old rats than in 3-week-old rats (Figure 1A). This impairment was larger in endothelium-denuded aortic rings than in aortic rings with intact endothelium. Maximal $\%$ of isoproterenol-induced relaxation was $100 \pm 0 \%$ compared with $77.3 \pm 2.1 \%$ in endothelium-intact aortic rings from 3- and 9-week-old rats, respectively. Whereas, isoproterenol-induced relaxation was $98.1 \pm 1.5 \%$ compared with $47.2 \pm 1.7 \%$ in endothelium-denuded aortic rings from 3- and 9-week-old rats, respectively (Figure 1A). No difference in aortic ring relaxation was observed with acetylcholine or sodium nitroprusside agonists treatment in either group.

\section{Relaxation response to adrenergic agonists in older rats}

To identify the possible adrenergic receptor involved in impaired adrenergic relaxation in 9-week-old rats, we tested different $\beta$-adrenergic agonists (Table 2). Dobutamine ( $\beta 1$ agonist, Figure $1 \mathrm{~B})$ and salbutamol ( $\beta 2$ agonist, Figure $1 \mathrm{C}$ ) induced dose-dependent aortic ring relaxation in both younger and older rats. There were no differences in relaxation responses between 3- and 9-week-old rats in the presence or absence of endothelium. BRL3744 ( $\beta 3$ agonist) induced concentration-dependent vascular relaxation in both groups; however, BRL3744-mediated aortic ring relaxation was lower in 9-week-old rats compared with that of younger rats (Figure 1D). BRL 3744-mediated impairment was more severe in endotheliumdenuded aortic rings than in endothelium-intact aortic rings. Maximal relaxation induced by BRL3744 was $31.4 \pm 4.5$ and $2.1 \pm 0.6 \%$ in endothelium-denuded aortic rings of 3- and 9-week-old rats, respectively, compared with $72 \pm 2.7$ and $10.2 \pm 2.5 \%$ in endothelium-intact aortic rings of 3 - and 9-week-old rats, respectively (Figure 1D). 


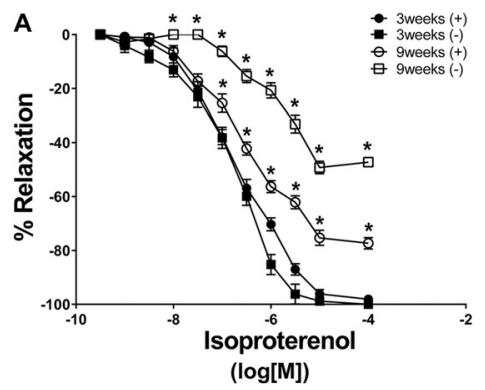

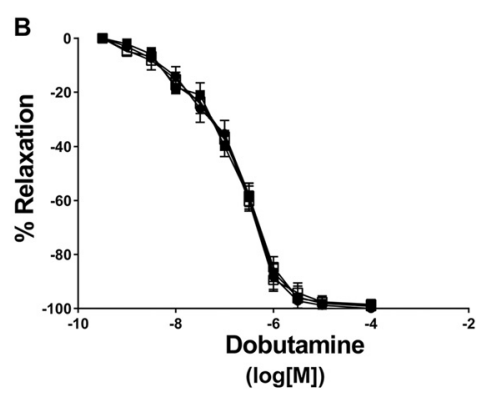

Figure 1. Concentration response curves in precontracted (treated with phenylephrine) aortic rings. The relaxant response to isoproterenol $(A)$, dobutamine $(B)$, salbutamol $(C)$, and BRL3744 (D) was evaluated in endothelium-intact aortic rings $(+)$ and endothelium-denuded aortic rings $(-)$ of 3- and 9-week-old rats. Data are reported as the mean \pm SE of 5 different animals. ${ }^{*} P<0.05$ vs 3-week-old (ANOVA followed by modified Newman Keuls $t$-test).

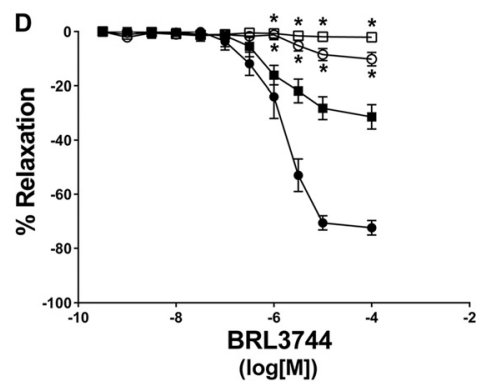

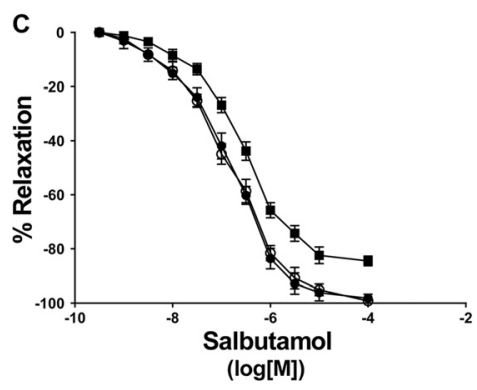

Table 2. pD2 values for $\beta$-adrenergic agonist-induced relaxation in aortic rings with $(+)$ and without $(-)$ endothelium.

\begin{tabular}{lcclcc}
\hline & \multicolumn{2}{c}{3 weeks } & & \multicolumn{2}{c}{9 weeks } \\
\cline { 2 - 3 } \cline { 5 - 6 } & $(+)$ & $(-)$ & & $(+)$ & $(-)$ \\
\hline Isoproterenol & $6.76 \pm 0.33$ & $6.76 \pm 0.33$ & & $6.13 \pm 0.30^{\#}$ & $4.92 \pm 0.10^{\#}$ \\
Dobutamine & $6.79 \pm 0.20$ & $6.79 \pm 0.20$ & & $6.74 \pm 0.10$ & $6.79 \pm 0.10$ \\
Salbutamol & $6.33 \pm 0.23$ & $6.33 \pm 0.23$ & & $6.82 \pm 0.10$ & $6.29 \pm 0.50$ \\
BRL37344 & $5.46 \pm 0.15$ & $5.46 \pm 0.15$ & & $3.10 \pm 0.40^{\#}$ & $2.37 \pm 0.30^{\#}$ \\
\hline
\end{tabular}

Data are reported as means $\pm \mathrm{SD}$. ${ }^{\#} \mathrm{P}<0.05$, compared to 3 -week-old rats (ANOVA followed by Newman Keuls test).

\section{Relaxation response to adrenergic antagonists in older rats}

To further explore the $\beta$-adrenergic subtypes involved in vascular relaxation impairment in older rats, we tested the effects of $\beta A R$ agonists in the presence of $\beta A R$ antagonists. The results are presented as $\mathrm{pD} 2$ values in Table 3. The presence of $\beta 1 A R$ antagonist CGP20712A inhibited dobutamine-induced relaxation, but did not affect salbutamol- or BRL3744-induced responses. The addition of $\beta 2 A R$ antagonist $\mathrm{ICl}-118,551$ inhibited isoproterenoland salbutamol-induced relaxation, but did not affect the dobutamine-induced response. The presence of $\beta 3 A R$ antagonist SR59230A inhibited BRL3744-induced relaxation, but did not affect dobutamine- and salbutamolinduced responses.

These antagonists were tested on isoproterenoland BRL3744-induced relaxation in aortic rings with and without endothelium. Isoproterenol-induced relaxation was tested in presence of specific $\beta A R$ antagonists (Figure 2).
The presence of $\beta 1 A R$ antagonist CGP20712A did not affect isoproterenol-dependent aortic ring relaxation in younger and older rats. Addition of the $\beta 2 A R$ antagonist $\mathrm{ICl}-118,551$ inhibited isoproterenol-dependent aortic ring relaxation in both groups (Figure 2A-D). The $\beta 3 A R$ antagonist SR59230A inhibited isoproterenol-dependent aortic ring relaxation in 3-week-old rats but not in 9-weekold rats. BRL3744-dependent vascular relaxation was not affected by the $\beta 1 A R$ antagonist CGP20712A or the $\beta 2 A R$ antagonist ICl-118,551 in either group. However, the $\beta 3 A R$ antagonist SR59230A inhibited BRL3744-dependent vascular relaxation in aortic rings of 3-week-old rats, but not in those of 9-week-old rats (Figure 3A-D).

\section{Differential protein expression of $\beta 1 A R, \beta 2 A R$, and $\beta 3 A R$}

Higher levels of $\beta 1 A R$ and $\beta 2 A R$ protein expression were detected in vascular tissue of 9-week-old rats compared with those of 3 -week-old rats). The protein 
Table 3. Relaxation induced by $\beta$-adrenergic agonists and specific antagonists on aortic rings with $(+)$ or without $(-)$ endothelium from 3- and 9-week-old rats.

\begin{tabular}{|c|c|c|c|c|}
\hline \multirow[t]{2}{*}{$\beta$-adrenergic agonists } & \multicolumn{2}{|c|}{3 weeks } & \multicolumn{2}{|c|}{9 weeks } \\
\hline & $(+)$ & $(-)$ & $(+)$ & $(-)$ \\
\hline Isoproterenol & $7.45 \pm 0.10$ & $7.46 \pm 0.20$ & $5.65 \pm 0.20$ & $4.92 \pm 0.19$ \\
\hline + CGP20712A & $7.46 \pm 0.20$ & $7.38 \pm 0.21$ & $5.40 \pm 0.23$ & $4.95 \pm 0.16$ \\
\hline$+\mathrm{ICl} 118551$ & $6.42 \pm 0.20^{\#}$ & $6.52 \pm 0.10^{\#}$ & $4.95 \pm 0.10^{\#}$ & $4.00 \pm 0.09^{\#}$ \\
\hline + SR59230A & $5.92 \pm 0.10^{\#}$ & $5.92 \pm 0.19^{\#}$ & $5.58 \pm 0.20^{\#}$ & $4.85 \pm 0.19^{\#}$ \\
\hline Dobutamine & $6.76 \pm 0.07$ & $6.79 \pm 0.02$ & $6.76 \pm 0.25$ & $6.79 \pm 0.10$ \\
\hline + CGP20712A & $6.06 \pm 0.17^{\#}$ & $6.20 \pm 0.12^{\#}$ & $6.22 \pm 0.48^{\#}$ & $6.08 \pm 0.17^{\#}$ \\
\hline$+\mathrm{ICl} 118551$ & $6.76 \pm 0.10$ & $6.79 \pm 0.10$ & $6.79 \pm 0.10$ & $6.79 \pm 0.09$ \\
\hline + SR59230A & $6.79 \pm 0.10$ & $6.72 \pm 0.09$ & $6.79 \pm 0.19$ & $6.79 \pm 0.06$ \\
\hline Salbutamol & $6.82 \pm 0.19$ & $6.33 \pm 0.12$ & $6.85 \pm 0.10$ & $6.29 \pm 0.40$ \\
\hline + CGP20712A & $6.85 \pm 0.09$ & $6.33 \pm 0.23$ & $6.53 \pm 0.29$ & $6.25 \pm 0.55$ \\
\hline + ICl118551 & $6.36 \pm 0.30^{\#}$ & $5.85 \pm 0.09^{\#}$ & $6.36 \pm 0.30^{\#}$ & $5.85 \pm 0.10^{\#}$ \\
\hline + SR59230A & $6.79 \pm 0.08$ & $6.30 \pm 0.19$ & $6.88 \pm 0.12$ & $6.34 \pm 0.27$ \\
\hline BRL3744 & $5.88 \pm 0.19$ & $3.82 \pm 0.10$ & $3.10 \pm 0.15$ & $2.37 \pm 0.12$ \\
\hline + CGP20712A & $5.85 \pm 0.10$ & $3.79 \pm 0.09$ & $3.16 \pm 0.13$ & $2.45 \pm 0.10$ \\
\hline$+\mathrm{ICl} 118551$ & $5.90 \pm 0.11$ & $3.79 \pm 0.07$ & $3.16 \pm 0.14$ & $2.33 \pm 0.10$ \\
\hline + SR59230A & $5.28 \pm 0.07^{\#}$ & $3.27 \pm 0.10^{\#}$ & $3.07 \pm 0.10^{\#}$ & $2.46 \pm 0.10^{\#}$ \\
\hline
\end{tabular}

pD2 values were obtained in the absence or presence of specific antagonists. ${ }^{\#} \mathrm{P}<0.05$, compared to the effect of specific agonist (one-way ANOVA followed by Newman Keuls test).
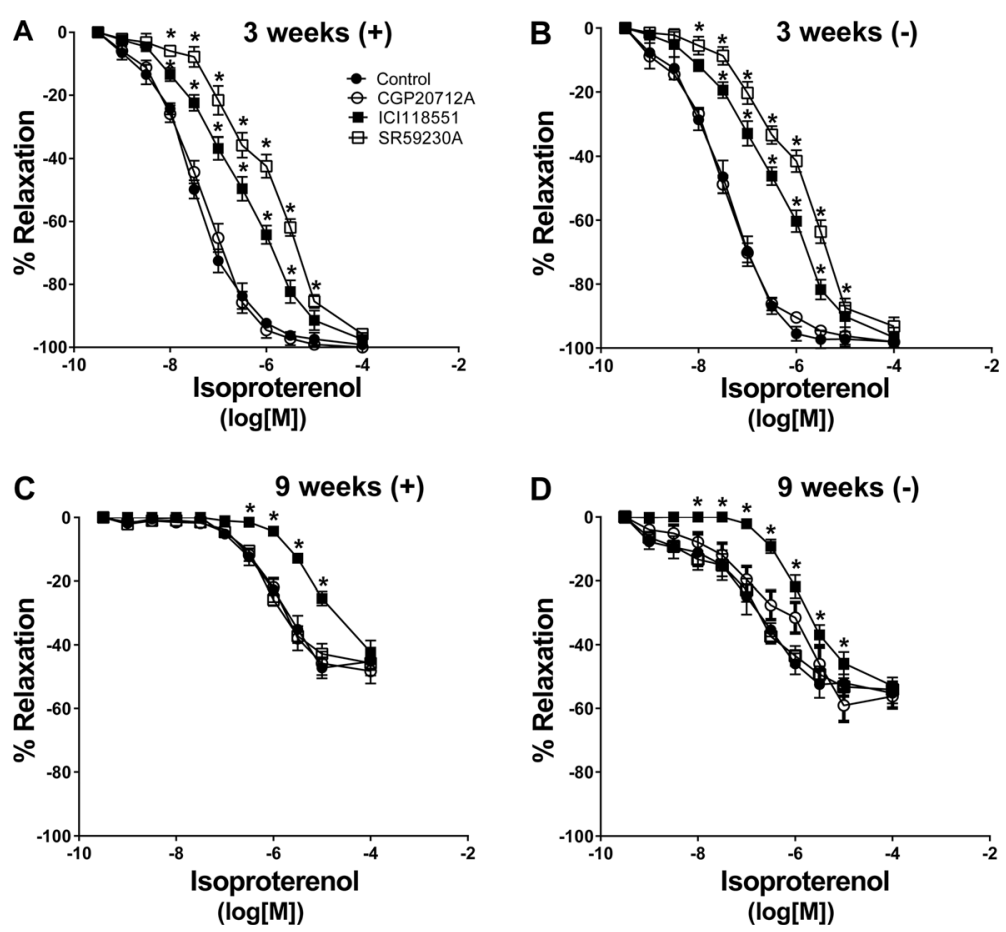

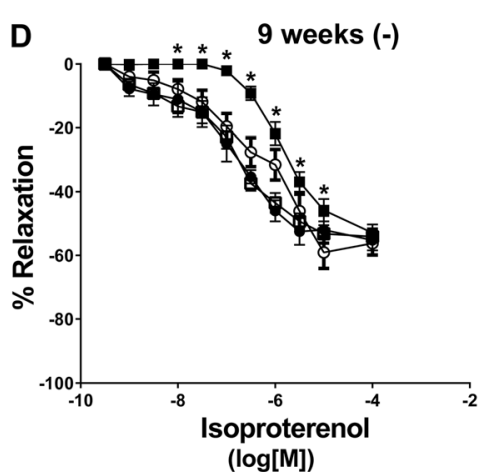

Figure 2. Concentration response curves in precontracted (treated with phenylephrine) aortic rings. The relaxant response to isoproterenol was evaluated in endothelium-intact aortic rings $(+)$ and endothelium-denuded aortic rings $(-)$ of 3- and 9-week-old rats in the absence or presence of the $\beta 1$ receptor antagonist CGP20712A $\left(10^{-7} \mathrm{M}\right)$, $\beta 2$ receptor antagonist ICI118551 $\left(10^{-7} \mathrm{M}\right)$, and $\beta 3$ receptor antagonist SR59230A $\left(10^{-7} \mathrm{M}\right)$. Data are reported as the mean $\pm S E$ of 5 different animals. ${ }^{*} \mathrm{P}<0.05$ vs control (ANOVA followed by modified Newman Keuls $t$-test). 

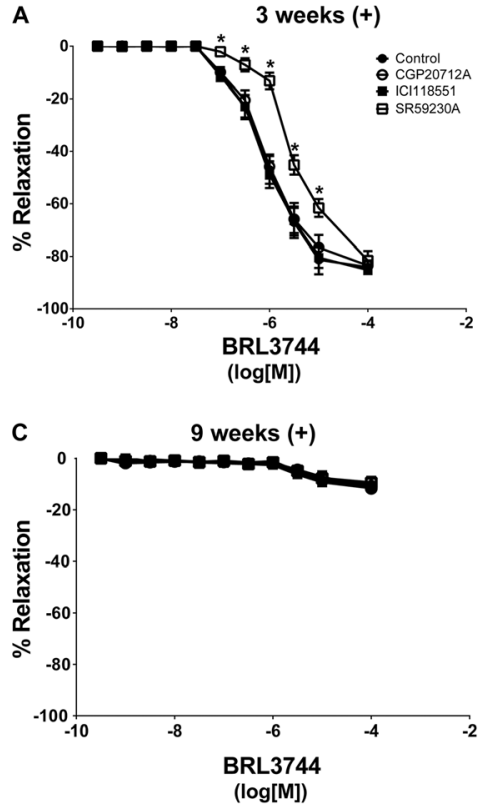

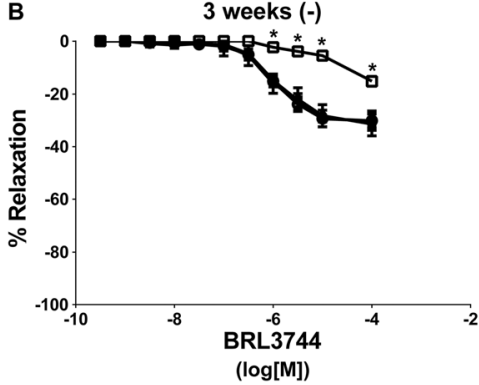

D

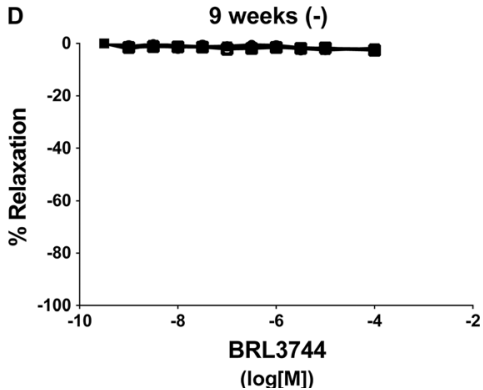

Figure 3. Concentration response curves in precontracted (treated with phenylephrine) aortic rings. The relaxant response to BRL3744 was evaluated in endothelium-intact aortic rings $(+)$ and endothelium-denuded aortic rings $(-)$ ( $A$ and $C)$ of 3- and 9-week-old rats $(B$ and $D)$ in the absence or presence of the $\beta 1$ receptor antagonist CGP20712A $\left(10^{-7} \mathrm{M}\right), \beta 2$ receptor antagonist $\mathrm{ICl} 118551\left(10^{-7} \mathrm{M}\right)$, and $\beta 3$ receptor antagonist SR59230A $\left(10^{-7} \mathrm{M}\right)$. Data are reported as the mean $\pm \mathrm{SE}$ of 5 different animals. ${ }^{*} \mathrm{P}<0.05 \mathrm{vs}$ control (ANOVA followed by modified Newman Keuls $t$-test).

A

$\beta 1$

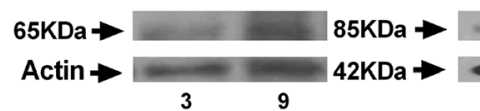

$\beta 2$

$\beta 3$

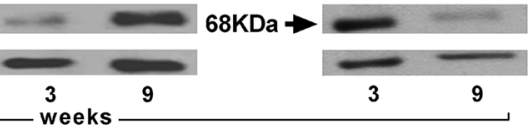

Figure 4. Comparative analysis of $\beta$-adrenergic receptor protein expression in aortic tissue of 3- and 9-week-old rats. The western blot is representative of 5 different experiments for each specific $\beta$ receptor, with actin used as control $(A)$. Graph represents the $\beta$-adrenergic receptor/actin ratio of 3- and 9-week-old rats $(B)$. Data are reported as the mean $\pm S E$ of 5 different rats. ${ }^{*} \mathrm{P}<0.05$ vs 3 -week-old rats (one-way ANOVA followed by Newman Keuls test).

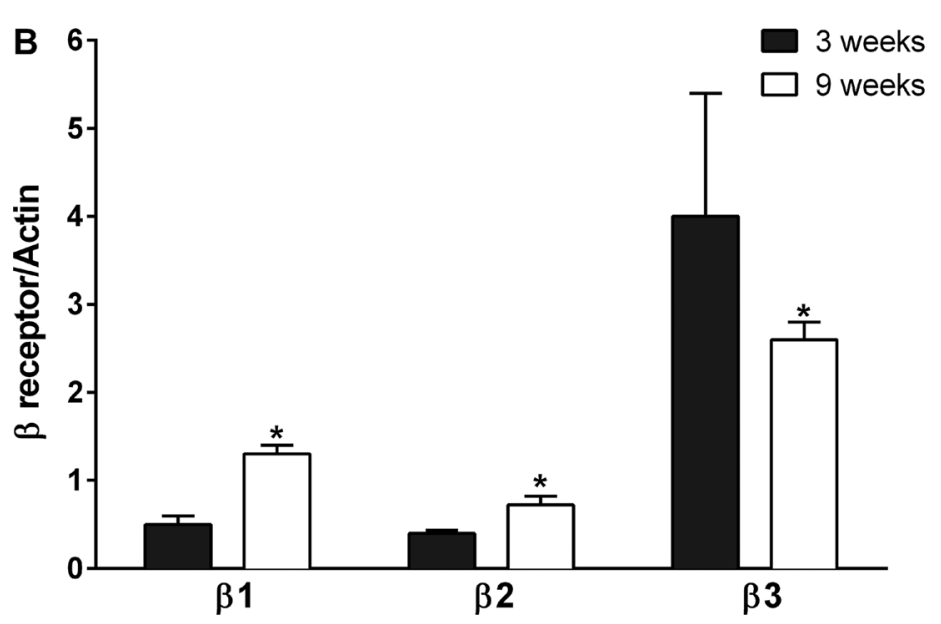

expression levels of $\beta 3 A R$ were lower in vascular tissue of 9-week-old rats compared with that in 3-week-old rats (Figure 4A and B). No differences were observed in $\beta 2 A R$ receptor phosphorylation under basal conditions or after isoproterenol stimulation in vascular tissue of younger and older rats (Figure $5 A$ and $B$ ).
Differential response to adenylyl cyclase pathway inhibitors

The adenylyl cyclase inhibitor SQ22536 and the protein kinase A inhibitor $\mathrm{H} 89$ significantly inhibited isoproterenol-induced vascular relaxation in aortic rings of 3 -week-old rats but not in those of 9-week-old rats 
A 3 weeks

Control Iso $15 \mathrm{~min}$ Iso $30 \mathrm{~min}$
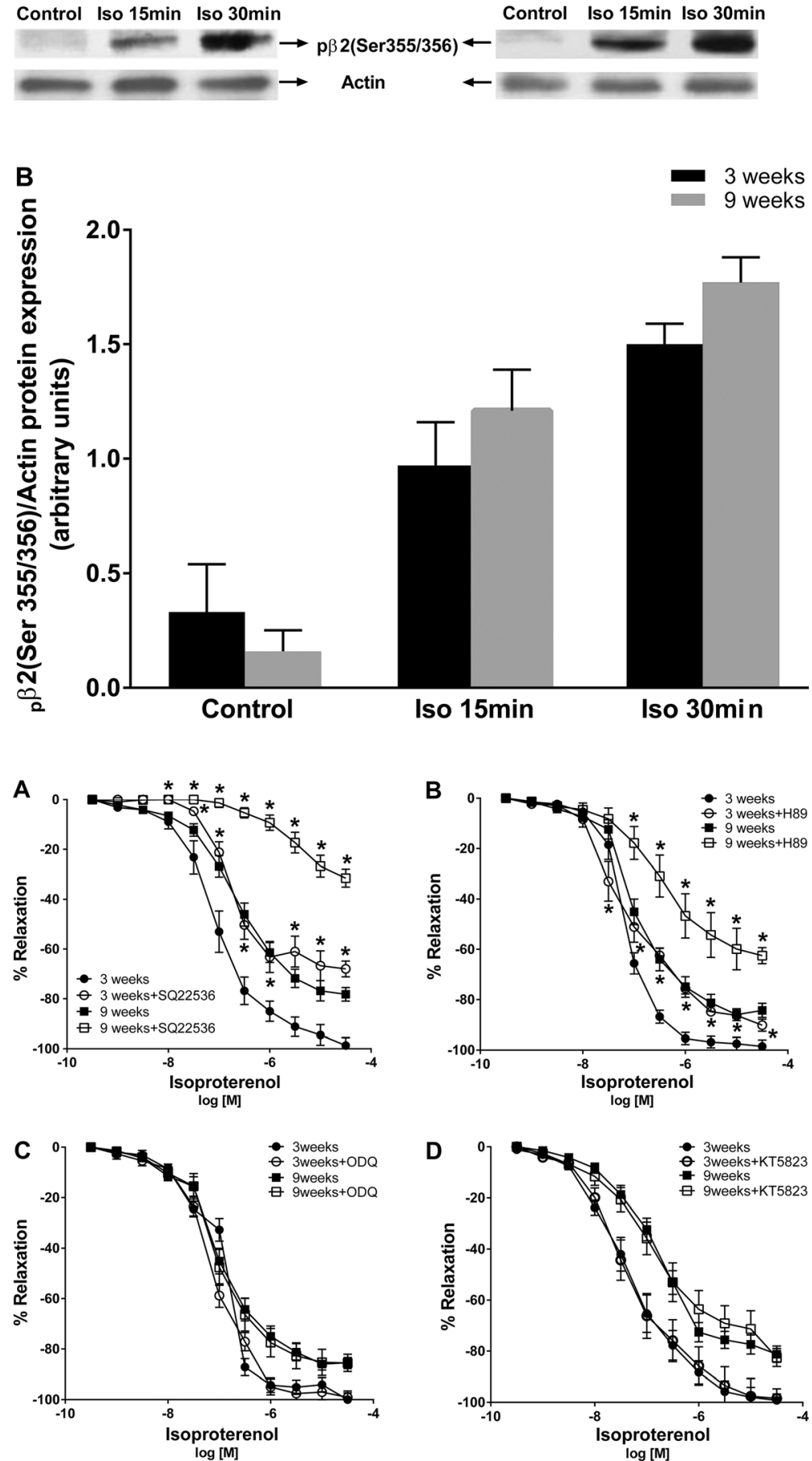
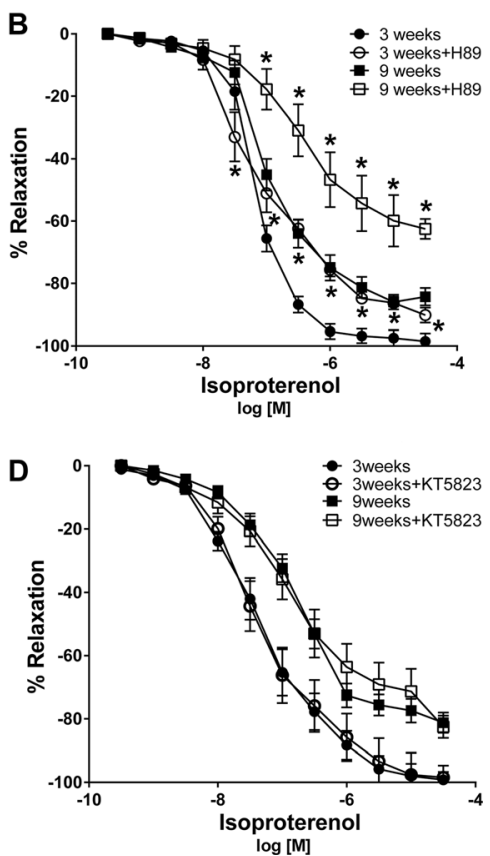

Figure 5. Comparative analysis of $\beta$-adrenergic receptor protein phosphorylation in aortic tissue of 3- and 9-week-old rats. Blots are representative of five different experiments, with actin as control $(A)$. $\beta$-adrenergic receptor phosphorylation was evaluated in the absence of receptor agonist (control) or in the presence of isoproterenol (Iso, $10^{-5} \mathrm{M}$ ). Aortic tissue of 3- and 9-week-old rats was analyzed 15 or 30 min after addition of Iso. Graph represents the ${ }_{p} \beta 2 / a c t i n$ ratio $(B)$. Data are reported as the mean \pm SE of 5 different rats.
(Figure 6A and $\mathrm{B}$ ). The guanylyl cyclase inhibitor ODQ and the PGK inhibitor KT75823 did not affect isoproterenolinduced relaxation in aortic rings of younger and older rats (Figure 6C and D).

CAMP production by aortic rings was measured after stimulation with isoproterenol. The results indicated that
CAMP production decreased in aortic rings of 9-week-old rats $(3.3 \pm 1 \mathrm{pmol} / \mathrm{mL})$ compared with that in 3-week-old rats $(20 \pm 2 \mathrm{pmol} / \mathrm{mL})$. Similar results were observed in the presence of the phosphodiesterase inhibitor rolipram $(8 \pm 1$ and $26 \pm 3 \mathrm{pmol} / \mathrm{mL}$ for 9- and 3-week-old rats). However, dose response curves of forskolin-induced 


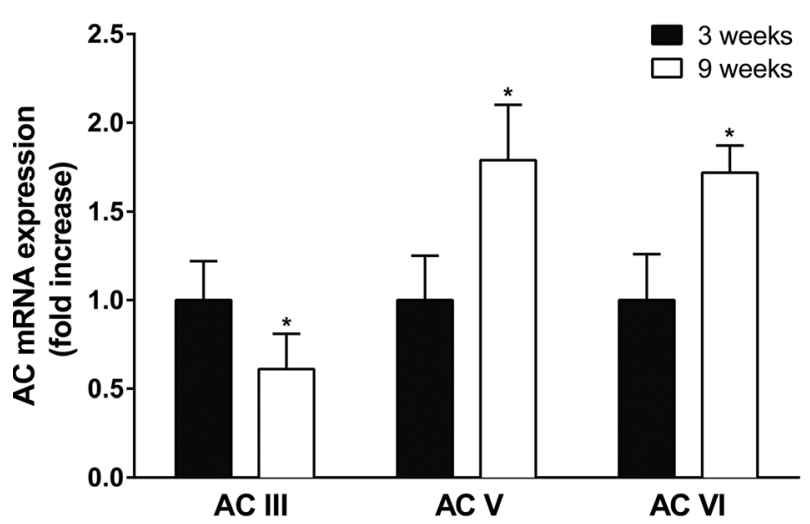

Figure 7. Comparative analysis of transcript abundance of adenylyl cyclase (AC) isoforms. qPCR was performed on CDNA from 3- and 9-week-old rats. The relative expression of AC III, V, or $\mathrm{VI}$ was calculated by the $2^{-\Delta \Delta C T}$ method and normalized with respect to the mean value of 3-week-old controls. All values were normalized. Data are reported as the mean \pm SE of 5 different animals. ${ }^{*} \mathrm{P}<0.05$ vs 3 -week-old rats (one-way ANOVA followed by Newman Keuls test).

vascular relaxation showed no differences between aortic rings from younger and older rats. Thus, pD2 values were $6.9 \pm 0.13$ and $6.6 \pm 0.2$, and cAMP production was $20 \pm 2$ and $25 \pm 5 \mathrm{pmol} / \mathrm{mL}$ for 3- and 9-week-old rats, respectively.

The expression of genes encoding adenylyl cyclase III, $\mathrm{V}$, and $\mathrm{VI}$ showed increased expression of type $\mathrm{V}$ and $\mathrm{VI}$ and decreased expression of type III in vascular tissue of 9-week-old rats compared with that in 3-week-old rats (Figure 7). The calcium-related protein RyR3 mRNA transcript levels increased $2.5 \pm 0.4$ fold in vascular tissue of 9-week-old rats compared with that in 3-week-old rats.

\section{Discussion}

In the present study, we demonstrated that vascular relaxation impairment is associated with maturation, and we suggest that changes in expression of genes encoding $\beta 3 A R$ and adenylyl cyclases are responsible for the altered vascular function. Our observation that vasorelaxation impairment induced by $\mathrm{ACh}$ or sodium nitroprusside did not change in 9-week-old rats compared with 3-week-old rats supports a specific role for $\beta A R$ in maturation-dependent vasorelaxation impairment, as described in previous studies (7). Reduced $\beta A R$-induced vasorelaxation associated with aging has been reported in several studies $(6,8,16-18)$, similarly to our results. However, the age of animals in those reports ranged from 6- to 24-month-old compared with 9-week-old rats used in the present study, suggesting that this effect is related to maturation rather than with aged animals.

The presence of several $\beta A R$ subtypes in rat aortic rings was demonstrated by the use of specific receptor agonists and antagonists and further supported by western blot. This suggests that all 3 adrenergic receptor subtypes are involved in the isoproterenol induced vasorelaxation, as reported previously (19). Beta adrenergic-dependent vasorelaxation has been described as endothelium-dependent and endothelium-independent in rat aorta $(20,21)$. Our data demonstrated that endothelium removal decreased salbutamol and BRL37344induced vasorelaxation but did not affect dobutamineinduced vasorelaxation (Table 2). Thus, we suggest that adrenergic-mediated vasorelaxation of the endothelium is related to the receptor involved.

Identification of the $\beta A R$ involved in maturationdependent vasorelaxation impairment was suggested by the decreased vasorelaxation in 9-week-old rats induced by specific $\beta 2$ and $\beta 3$ agonists, and supported by the absence of inhibitory effect of specific antagonists. More over, decreased expression of the $\beta 3$ receptor further supports the role of this receptor in the impaired vasorelaxation.

Relaxation impairment is more evident if endothelium has been removed $(53 \pm 3 \%$ in endothelium-denuded arteries) compared with endothelium-intact rings (33 $\pm 4 \%)$. This result suggests an important change of the adrenergic signaling pathway in smooth muscle cells. This is in agreement with a report showing reduction in isoproterenol-induced CAMP accumulation in cultured smooth muscle cells obtained from older rats (22).

Because no differences in $\beta 2$ adrenergic receptor phosphorylation were observed in younger and older rats, we suggest that vasorelaxation impairment in 9-week-old rats was not associated with changes in receptor activation.

Adenylyl cyclase stimulation with cAMP production is the classical AR signaling pathway in vascular smooth muscle (23). Therefore, we explored cAMP pathway as being responsible for the age-maturation impairment. In older rats, there was a reduction of cAMP-dependent $\beta 3$ vasorelaxation, which was evidenced by the fact that neither adenylyl cyclase inhibitors nor PKA inhibitors affected isoproterenol-induced relaxation in aortic rings from 9-week-old rats. cAMP production was reduced in aortic rings from 9-week-old rats, which further supports the hypothesis that the isoproterenol effect was no longer cAMP-dependent in older rats. Reduced cAMP production can be explained by reduced initial stimulus, reduced adenylyl cyclase activation, or elevated phosphodiesterase activation. Forskolin-induced adenylyl cyclase activity did not differ in aortic ring relaxation in younger and older rats suggesting that cAMP activation is not the mechanism involved in the age-maturation cAMP reduction. However, adenylyl cyclase III expression was reduced in vascular tissue of 9-week-old rats, suggesting that reduced cAMP levels may result from a change in adenylyl cyclase subtype that interacts with $\beta$-receptors. The calcium receptor RyR3 expression levels increased in 
9-week-old rats. Adenylyl cyclase calcium-dependent regulation has been associated with adenylyl cyclase inhibition rather than phosphodiesterase activation (24). Cytoplasmic calcium levels are reported to regulate adenylyl cyclase activity in vascular smooth muscle cells $(25,26)$. Therefore, our data suggest that reduced cAMP production in 9-week-old rats was associated with increased calcium levels and to increased RyR3 receptor, which inhibits adenylyl cyclase III isoform in aortic rings.

The present results indicate that impaired $\beta A R$ relaxation may be associated with age maturation. Our results showed evidence of this process at the onset of

\section{References}

1. Oriowo MA. Different atypical beta-adrenoceptors mediate isoprenaline-induced relaxation in vascular and non-vascular smooth muscles. Life Sci 1995; 56: L269-L275, doi: 10.1016/ 0024-3205(95)00076-3.

2. Begonha R, Moura D, Guimaraes S. Vascular betaadrenoceptor-mediated relaxation and the tone of the tissue in canine arteries. J Pharm Pharmacol 1995; 47: 510-513, doi: 10.1111/j.2042-7158.1995.tb05840.x.

3. Guimaraes S, Moura D. Vascular adrenoceptors: an update. Pharmacol Rev 2001; 53: 319-356.

4. Gauthier C, Langin D, Balligand JL. Beta3-adrenoceptors in the cardiovascular system. Trends Pharmacol Sci 2000; 21: 426-431, doi: 10.1016/S0165-6147(00)01562-5.

5. Ericsson E, Lundholm L. Adrenergic beta-receptor activity and cyclic AMP metabolism in vascular smooth muscle; variations with age. Mech Ageing Dev 1975; 4: 1-6, doi: 10.1016/0047-6374(75)90002-0.

6. Schutzer WE, Mader SL. Age-related changes in vascular adrenergic signaling: clinical and mechanistic implications. Ageing Res Rev 2003; 2: 169-190, doi: 10.1016/S1568-1637 (02)00063-6.

7. Kazanietz MG, Enero MA. Decreased beta-adrenoceptormediated vasodilation in aorta from aged rats: possible involvement of a stimulatory GTP-binding protein. Eur $J$ Pharmacol 1991; 198: 177-181, doi: 10.1016/0014-2999(91)90618-Z.

8. Schutzer WE, Xue H, Reed JF, Mader SL. Effect of age on vascular beta2-adrenergic receptor desensitization is not mediated by the receptor coupling to Galphai proteins. $J$ Gerontol A Biol Sci Med Sci 2006; 61: 899-906, doi: 10.1093/gerona/61.9.899.

9. Gaballa MA, Eckhart AD, Koch WJ, Goldman S. Vascular beta-adrenergic receptor adenylyl cyclase system in maturation and aging. J Mol Cell Cardiol 2000; 32: 1745-1755, doi: 10.1006/jmcc.2000.1210.

10. Baloglu E, Kiziltepe O, Gurdal H. The role of Gi proteins in reduced vasorelaxation response to beta-adrenoceptor agonists in rat aorta during maturation. Eur J Pharmacol 2007; 564: 167-173, doi: 10.1016/j.ejphar.2007.02.054.

11. Xiao RP, Cheng H, Zhou YY, Kuschel M, Lakatta EG. Recent advances in cardiac beta(2)-adrenergic signal transduction. Circ Res 1999; 85: 1092-1100, doi: 10.1161/01.RES.85. 11.1092

12. Xiao RP, Avdonin $\mathrm{P}$, Zhou $\mathrm{YY}$, Cheng $\mathrm{H}$, Akhter SA, Eschenhagen $\mathrm{T}$, et al. Coupling of beta2-adrenoceptor to sexual maturation. Therefore, we suggest that increased male sexual hormones promote changes in the AR signaling pathway as part of physiological blood vessel maturation. Impaired $\beta A R$ relaxation present in adult or older rats may be associated with blood vessel damage. Thus, the role of testosterone related to changes in vascular response requires further investigation.

\section{Acknowledgments}

Oscar López-Canales is a fellow from Consejo Nacional de Ciencia y Tecnología (CONACyT), Mexico.

Gi proteins and its physiological relevance in murine cardiac myocytes. Circ Res 1999; 84: 43-52, doi: 10.1161/01.RES. 84.1.43.

13. Liggett SB, Freedman NJ, Schwinn DA, Lefkowitz RJ. Structural basis for receptor subtype-specific regulation revealed by a chimeric beta 3/beta 2-adrenergic receptor. Proc Natl Acad Sci U S A 1993; 90: 3665-3669, doi: 10.1073/pnas.90.8.3665.

14. Oliver E, Marti D, Monto F, Flacco N, Moreno L, Barettino D, et al. The impact of alpha1-adrenoceptors up-regulation accompanied by the impairment of beta-adrenergic vasodilatation in hypertension. J Pharmacol Exp Ther 2009; 328: 982-990, doi: 10.1124/jpet.108.146043.

15. Mizuno K, Kanda Y, Kuroki Y, Nishio M, Watanabe Y. Stimulation of beta(3)-adrenoceptors causes phosphorylation of p38 mitogen-activated protein kinase via a stimulatory $G$ protein-dependent pathway in 3T3-L1 adipocytes. Br J Pharmacol 2002; 135: 951-960, doi: 10.1038/sj. bjp.0704537.

16. Tsujimoto $\mathrm{G}$, Lee $\mathrm{CH}$, Hoffman BB. Age-related decrease in beta adrenergic receptor-mediated vascular smooth muscle relaxation. J Pharmacol Exp Ther 1986; 239: 411-415.

17. Omar NM, Abbas AM, Abdel-Malek $H$, Suddek GM. Effect of age on the contractile response of the rat carotid artery in the presence of sympathetic drugs and L-NAME. Acta Physiol Hung 2013; 100: 266-279, doi: 10.1556/ APhysiol.100.2013.3.3.

18. Schutzer WE, Xue H, Reed J, Oyama T, Beard DR, Anderson $\mathrm{S}$, et al. Age-related beta-adrenergic receptormediated vasorelaxation is changed by altering $G$ protein receptor kinase 2 expression. Vascul Pharmacol 2011; 55: 178-188, doi: 10.1016/j.vph.2011.09.001.

19. Flacco N, Segura V, Perez-Aso M, Estrada S, Seller JF, Jimenez-Altayo $\mathrm{F}$, et al. Different beta-adrenoceptor subtypes coupling to CAMP or NO/cGMP pathways: implications in the relaxant response of rat conductance and resistance vessels. Br J Pharmacol 2013; 169: 413-425, doi: 10.1111/ bph.12121.

20. Ferro A, Coash M, Yamamoto T, Rob J, Ji Y, Queen L. Nitric oxide-dependent beta2-adrenergic dilatation of rat aorta is mediated through activation of both protein kinase $A$ and Akt. Br J Pharmacol 2004; 143: 397-403, doi: 10.1038/ sj.bjp.0705933. 
21. Satake N, Shibata M, Shibata $S$. The inhibitory effects of iberiotoxin and 4-aminopyridine on the relaxation induced by beta 1- and beta 2-adrenoceptor activation in rat aortic rings. Br J Pharmacol 1996; 119: 505-510, doi: 10.1111/j.14765381.1996.tb15700.x.

22. Schutzer WE, Beard DR, Reed JF, Mader SL. Characterization of clonal vascular smooth muscle cell lines derived from young and old Fischer 344 rats. In Vitro Cell Dev Biol Anim 2011; 47: 445-450, doi: 10.1007/s11626-011-9430-7.

23. Murray KJ. Cyclic AMP and mechanisms of vasodilation. Pharmacol Ther 1990; 47: 329-345, doi: 10.1016/01637258(90)90060-F
24. Demirel E, Ugur O, Onaran $\mathrm{HO} . \mathrm{Ca}^{2+}$-induced inhibition of adenylyl cyclase in turkey erythrocyte membranes. Pharmacology 1998; 57: 222-228, doi: 10.1159/000028245.

25. Ahuja M, Jha A, Maleth J, Park S, Muallem S. cAMP and $\mathrm{Ca}(2)(+)$ signaling in secretory epithelia: crosstalk and synergism. Cell Calcium 2014; 55: 385-393, doi: 10.1016/ j.ceca.2014.01.006.

26. Zhang J, Sato M, Duzic E, Kubalak SW, Lanier SM, Webb JG. Adenylyl cyclase isoforms and vasopressin enhancement of agonist-stimulated cAMP in vascular smooth muscle cells. Am J Physiol 1997; 273: H971-H980. 